УДК 519.876.5:621.311.243

(C) 2014

Калініченко А. В., доктор сільськогосподарських наук

Полтавська державна аграрна академія, Опольський університет (м. Ополе, Польща)

Титко Р., кандидат сільськогосподарських наук

Об`єднання шкіл електричних (м. Краків, Польща)

Сакало В. М., кандидат технічних наук,

Горб О. О., кандидат сільськогосподарських наук

Полтавська державна аграрна академія

\title{
ВИКОРИСТАННЯ МЕТОДІВ МАТЕМАТИЧНОГО МОДЕЛЮВАННЯ ДЛЯ ОПТИМІЗАЦЇ̈ РЕЖИМІВ РОБОТИ ГЕЛІОСИСТЕМ
}

\section{Рецензент - доктор сільськогосподарських наук П. В. Писаренко}

Проаналізовано можливості використання методів математичного моделювання під час створення, аналізу та впровадження геліосистем на основі даних, отриманих у лабораторіях відновлюваних джерел енергї. У результаті проведених досліджень виявлено особливості впливу обраних параметрів роботи геліоустановки на теплову продуктивність теплообмінника. Дослідження ефективності сонячного вакуумного колектора й результати моделювання довели доцільність використання изього виду обладнання.

Ключові слова: модель, фактор, оптимізація, геліосистема, вплив.

Постановка проблеми. Ознаки світової енергетичної кризи, що почали з'являтися наприкінці минулого століття, сьогодні постають перед суспільством усе частіше та гостріше. Відсутність чіткої політики ціноутворення нафти та інших видів традиційних енергоносіїв ставить під питання динамічний розвиток країн, які роблять ставку на імпорт цієї сировини [3]. Членство в Європейському Союзі зобов'язує Польщу вирішувати проблеми отримання частини енергії $з$ відновлювальних джерел, відсоток якої у паливно-енергетичному балансі країни в 2010 році становив $\approx 7,5 \%$ [11]. До 2020 року Польща повинна отримувати з відновлювальних джерел не менше $15 \%$ від загального обсягу енергії [13].

Аналіз останніх досліджень i публікацій, у яких започатковано розв'язання проблеми. Нині у Польщі триває процес пошуку найкращих методів оптимізації процесу отримання теплової енергії з відновлюваних джерел [8].
Сучасні технічні рішення у сфері використання енергії сонця відкривають нові можливості щодо виробництва теплової енергії [10]. У значній кількості публікацій та наукових досліджень обговорюється питання підбору оптимальних режимів роботи геліосистем [2, 4, 12, 14-16].

Метою нашого дослідження було вивчення ефективності використання методів математичного моделювання для оптимізації технологічних режимів експлуатації геліосистем у лабораторних умовах.

Завдання: визачити фактори впливу на роботу геліосистем; проаналізувати взаємодію цих факторів та побудувати математичну модель для отримання оптимального кінцевого результату.

Матеріали і методи досліджень. Геліоустановка - це система обладнання для перетворення енергії сонячного випромінювання у теплову енергію.

Зазвичай до комплекту геліосистеми входять сонячні колектори з адсорбуючими панелями, теплові накопичувачі або бак-акумулятори 3 проточними теплообмінниками, насосна група, система трубопроводів, що пов'язує між собою обладнання, система гарячого водопостачання та мікроконтролер або цифровий регулятор для управління геліосистемою.

Геліоустановки знаходять застосування, як в окремих господарствах, так і в готелях, пансіонатах, центрах відпочинку, промислових та громадських установах, спортивних і рекреаційних закладах, басейнах, а також у сільському господарстві [7].

Баланс енергії $\left(\Delta Q_{z}\right)$ для системи сонячний колектор - бак-акумулятор, що є посередником в обміні тепла, розрахувався за формулами [7]: 


$$
\Delta Q_{z}=Q_{u}-L_{s}-Q_{\text {вmpam }}
$$

де: $Q_{u}$ - потік корисної енергії [Вт · год]; $L_{s}$ - витрати енергії на теплозабезпечення; $Q_{\text {вmрат }}-$ теплові втрати на колекторі та трубопроводах.

У нашому випадку, для спрощення розрахунків, вважали, що бак та трубопроводи добре ізольовані і практично не мають втрат тепла, отже скористалися наступним припущенням: $Q_{\text {втрат }}=0$.

Потік корисної теплової енергії складається з теплової енергії, отриманої від сонячного колектора й енергії догрівання від додаткового джерела тепла підключеного послідовно з бак-акумулятором,

$$
\begin{aligned}
& Q_{\text {геліосист }}=m_{\text {гвп }} \cdot c_{\theta} \cdot\left(T_{n p}-T_{x в}\right), \\
& Q_{\text {дод джсрела }}=m_{\text {гви }} \cdot c_{\theta} \cdot\left(T_{\text {гвn }}-T_{n p}\right),
\end{aligned}
$$

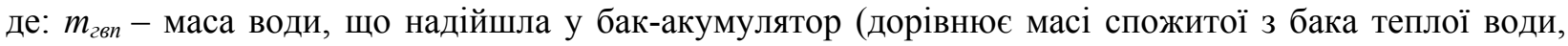
(кг); $T_{2 в n}$ - температура, до якої необхідно підігрівати гарячу воду $\left({ }^{\circ} \mathrm{C}\right) ; T_{n p}-$ температура, до якої догріває геліосистема $\left({ }^{\circ} \mathrm{C}\right) ; T_{x в}-$ температура холодної води, що поповнює бак-акумулятор $\left({ }^{\circ} \mathrm{C}\right)$.

У свою чергу кількість корисної теплової енергії, отриманої від сонячного колектора дорівнюватиме

$$
Q_{\text {геліссист }}=Q_{\text {опр }} \cdot A \cdot \eta,
$$

де: $Q_{\text {опр }}$ - інтенсивність сонячного випромінення; $A=A_{\kappa} \cdot n_{\kappa}=2,57 \cdot 2=5,14 \mathrm{м}^{2}, A$ - площа абсорбера одного колектора, $\eta$ - ККД.

Витрати енергії на теплозабезпечення залежать від споживання води в системі гарячого водопостачання

$$
L_{s}=m_{2 в n} \cdot c_{B} \cdot\left(T_{z, \tau+\Delta \tau}-T_{z, \tau}\right),
$$

де: $T_{z, \tau}-$ температура води в бак-акумуляторі на початку аналізованого проміжку часу $\left({ }^{\circ} \mathrm{C}\right) ; T_{z, \tau+\Delta \tau}-$ температура води в бак-акумуляторі в кінці аналізованого проміжку часу $\left({ }^{\circ} \mathrm{C}\right)$;

Водночас ККД самих сонячних колекторів становить:

$$
\eta=\frac{Q_{u}}{A \cdot Q_{\text {onp }}}
$$

Розрахунок ступеню покриття потреб у ГВП за рахунок геліосистеми:

$$
\varepsilon=\frac{Q_{\text {геліосист }}-Q_{\text {дод джерела }}}{Q_{\text {геліосист }}}
$$

Річна ж ефективність сонячної установки визначалася за формулою:

$$
\varepsilon^{p}=\frac{Q_{2}}{Q_{1}}=\frac{Q_{2}}{m \cdot c_{p} \cdot\left(T_{2}-T_{1}\right)},
$$

де: $Q_{1}$ - енергія, необхідна для нагріву ГВП упродовж року [кВт.год]; $Q_{2}$ - енергія, отримана геліоустановкою впродовж року [кВт·год] - згідно з показами лічильника; $T_{2}$ - температура гарячої води для користування (близько $55^{\circ} \mathrm{C}$ ); $T_{l}$ - температура води, що заходить у теплообмінник із системи водозабезпечення (близько $\left.7^{\circ} \mathrm{C}\right) ; c_{p}-$ теплоємність води [Дж/кг $\left.{ }^{\circ} \mathrm{C}\right] ; m-$ маса гарячої води [кг].

Для умов, коли сонячна установка не працює, ми приймали $\varepsilon=0$, для умов, коли сонячна установка постачає $100 \%$ необхідної енергії, $-\varepsilon=1$.

На основі наведених вище формул нами було розраховано енергетичний вклад геліосистеми у надходження енергії до комплексної системи теплопостачання.

Результати досліджень. У лабораторії відновлювальних джерел енергії в Об`єднанні шкіл електричних (ОШЕ) № 1 міста Краків нами було проведено комплекс досліджень 3 аналізу ефективності застосування сонячних колекторів у Малопольському регіоні. Схема досліджуваної установки наведена на рисунку 1. Предметом дослідження була геліосистема, до складу якої входять сонячні колектори з вакуумними трубками. Вони мають 30 труб heat-pipe 3 діаметром 58 мм і довжиною 1800 міліметрів. Розміри колектора 1990 мм у висоту і 2456 мм у ширину, загальною площею $4,8 \mathrm{~m}^{2}$, площа активного поглинання $5,14 \mathrm{~m}^{2}$. 


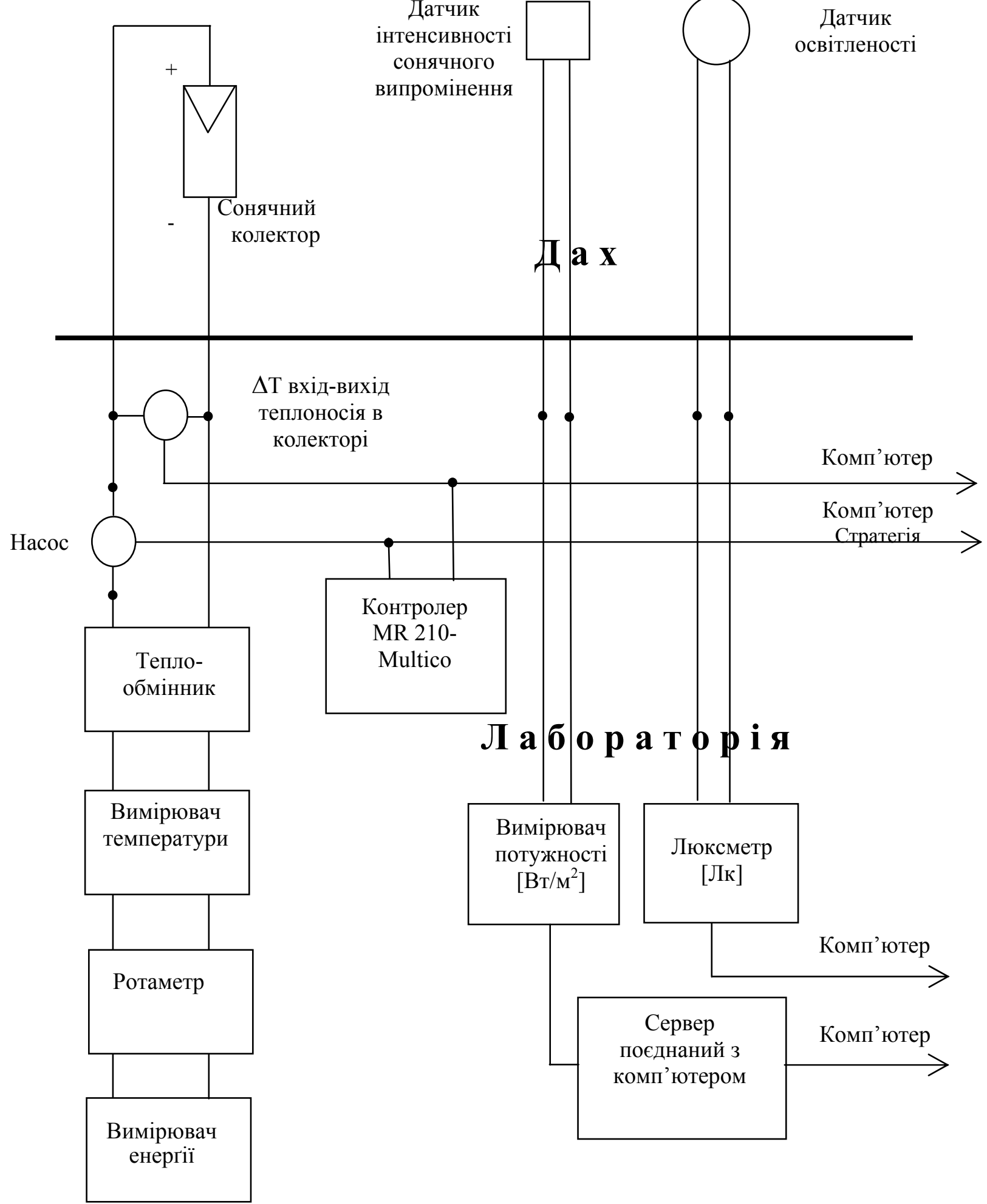

Рис. 1. Функціональна схема установки для дослідження геліосистем

Колектор з'єднаний ізольованими мідними трубами перерізом 18 мм із бак-акумулятором об'ємом 300 літрів. Колектори встановлено на даху в південному напрямку під кутом $45^{\circ} \mathrm{C}$. Система також включає в себе розширювальний бак системи захисту від перегріву, запобіжний клапан, вимірювач потужності, електронний контролер, датчики температури. Значення параметрів сонячного колектора реєструвалися теплолічильником - KFAP APATOR, підключеним 


\section{ТЕХНІЧНІ НАУКИ}

до сервера і комп'ютера. Системою керував контролер фірми Frisko. Вимірювання потужності сонячного випромінювання здійснювалися за допомогою вимірювача LB-900, і результати автоматично зберігалися на жорсткому диску. У ході досліджень перебігу процесу отримання теплової енергії із сонячної нами реєструвалися наступні дані: вихідна енергія (МДж), потужність (кВт), температура води ( $\left.{ }^{\circ} \mathrm{C}\right)$, витрата води (л/год), температура в баку для зберігання води $\left({ }^{\circ} \mathrm{C}\right)$. Дослідження проводилося на обладнанні фірми Insbud.

Установка працювала під контролем вільнопрограмувального контролера MR210-MULTICO, що містить відносно велику кількість входів і виходів різноманітної архітектури й два послідовних порти, забезпечуючи широкі можливості поєднання із зовнішніми пристроями.

Ці переваги будови контролера в поєднанні з перевагами програмних засобів ідеально підходять для більшості сучасних систем автоматизації 3 кількома джерелами тепла (системи 3 сонячними колекторами, теплообмінниками, тепловими насосами, котлами на вугіллі, дровах, каміни 3 водяною системою і т. д.). Особливо корисною в таких системах $\epsilon$ можливість безперервного контролю продуктивності малих насосів або вентиляторів (симісторний вихід) і здатність контролювати інвертори, пальники, модульовані приводами постійного струму з напругою 0-10 В (системи вентиляції та кондиціонування повітря).

Контролер може також працювати як пристрій типу «Чорна скринька», без дисплея і клавіатури, дистанційно передаючи дані через послідовний інтерфейс, LAN/WAN або GSM-мережі, реалізуючи автономне управління роботою системи. Широкі можливості інтерфейсу, у свою чергу, дають змогу використовувати контролер для розподілених систем контролю та управління, зокрема, в системах типу інтелектуальна будівля, які використовують MODBUS-RTU.

Математична модель управління геліосистемою. Під час математичного моделювання процесів, що відбуваються в геліосистемі, остання була прийнята нами як «чорна скринька» (рис. 2).

Було проведено аналіз роботи геліосистеми на основі теоретичної моделі, розробленої спираючись на існуючий математичний апарат, і статистично-дослідної моделі, побудованої на основі власних досліджень (Kopecki M., 1976 [8]; Gireń J., 1982 [6]; Górecka R, 1996 [5]; Bilicki Z., 1996 [1]).

Під час математичного моделювання процесів, що відбуваються в тих чи інших пристроях для отримання енергіï 3 відновлювальних джерел, вони сприймалися нами як «чорна скринька», де вхідними величинами $є$ змінні (досліджувані) параметри, а вихідними є параметри роботи системи, вимірювані за допомогою різних приладів.

Загальний вигляд математичної моделі досліджуваного процесу можна записати у вигляді рівняння: $y_{k}=f\left(x_{1}, x_{2}, x_{3}, \ldots, x_{\mathrm{n}}\right)$ для $c_{1}, c_{2}, c_{\mathrm{i}} \ldots=$ const.

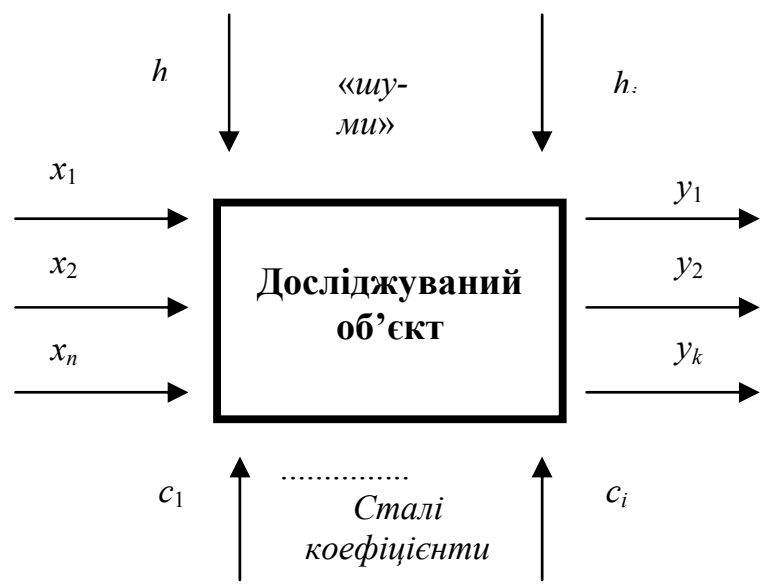

\section{Рис. 2. Схема автоматичного регулювання об'єктом досліджень (геліосистемою)}

Метою оптимізації є визначення екстремумів.

Опис модельованої системи рівнянь здійснювався на основі рівнянь регресії другого ступеня 3 інтеракціями. Застосування методу математичного моделювання й обробки, автоматизація результатів досліджень дали змогу змінити стратегію реалізації експериментів, що можна охарактеризувати наступними властивостями:

- рандомізація експериментів - цільове впровадження до досліджень концепції випадку через детально означену програму реалізації експериментів;

- одночасна зміна усіх досліджуваних факторів.

Це дало можливість досить докладно описати ефекти впливу окремих досліджуваних факторів (змінних параметрів) на вихідні параметри і співзалежності між ними, так звані інтеракції, чого не можна досягнути в дослідженнях традиційними методами. Розмірність досліджуваного факторного простору збільшується зі зростанням кількості факторів дослідження й ефекту від цього. Отримані результати були тим достовірнішими, чим більша кількість незалежних параметрів одночасно досліджувались.

Математично-статистичний аналіз отриманих результатів досліджень є можливим тільки з використанням комп'ютерної техніки із застосуванням спеціалізованих програмних продуктів пакету AutoGraf (входять до комплекту забезпечення мікроконтролера фірми Frisko, платформа MetaTrader 4 Admiral 


\section{TEХНІЧНІ НАУКИ}

Markets AS, 2010) з огляду на складність обчислень i необхідність проведення альтернативних розв'язань функції багатьох змінних.

Пакет програмного забезпечення AutoGraf для контролера MR210 є інструментом для DOS- систем, призначений для редагування структури, організації взаємодії з контролером (підтримка клавіатури і дисплея), для компіляції й завантаження складеної структури пам'яті.

Загальний вигляд математичної моделі для змінних параметрів $x_{i}$ був записаний таким чином:

$$
y=b_{0}+\sum_{i=1}^{4} b_{i} x_{i}+\sum_{i \leq j}^{4} b_{i j} x_{i} x_{j}+\sum_{i=1}^{4} b_{i i} x_{i}^{2}
$$

Коефіцієнти регресії визначено відповідно до наступних залежностей:

$$
\begin{gathered}
b_{0}=\frac{\sum_{u=1}^{N} \bar{y}_{u}}{N} \quad b_{i j}=\frac{\sum_{u=1}^{N} t_{i u} t_{j u} \bar{y}_{u}}{16} \\
b_{i}=\frac{\sum_{u=1}^{N} t_{i u} \bar{y}_{u}}{\sum_{u=1}^{N} t_{i u}{ }^{2}} \quad b_{i i}=\frac{\sum_{u=1}^{N} t_{i u} \bar{y}_{u}}{\sum_{u=l}^{N} t_{i u}^{\prime 2}} \quad \text { де } t_{i u}^{\prime}=t_{i u}{ }^{2}-\frac{\sum_{u=1}^{N} t_{i u}{ }^{2}}{N},
\end{gathered}
$$

де: $y_{u}$ - середнє значення кожного вихідного параметра; $N$ - кількість експериментів в матриці планування наукових досліджень; $t_{i u}, t_{j u}-$ відповідні значення елементів матриці, взяті із вибірки \pm 2 , $\pm 1,0$.

Перевірку адекватності емпіричних співвідношень проводили за допомогою дисперсійного аналізу:

$$
\begin{gathered}
S_{R}=\sum_{u=1}^{N}\left(y_{u}-\bar{y}_{u}\right)^{2} \\
S_{R}^{2}=\frac{S_{R}}{f_{R}}, \text { де } f_{R}=N-k,
\end{gathered}
$$

де: $S_{R}^{2}$ - різниця остаточного рівняння регресії; $f_{R}$ - кількість ступенів свободи; $N$ - кількість експериментів в матриці планування; $k$ - кількість одночленів у рівнянні регресії.

Початкову гіпотезу $H_{0}$ адекватності математичної моделі було перевірено за критерієм Фішера:

$$
F_{0}=\frac{S_{R}^{2}}{S^{2}} \leq F_{\text {крит }}(p, f) .
$$

У моделі було враховано конструкційні та технологічні особливості комплексної системи теплозабезпечення, що можуть вплинути на іiі роботу й вихідні (термофізичні) параметри роботи інсталяції, що характеризують ефективність іiі роботи. Математична модель характеризується високим ступенем адекватності щодо експериментальних досліджень.

Похибка між теоретичними та практичними значеннями в описанні термодинамічних явищ, що проходять у комплексній системі енергозабезпечення становить не більше $10 \%$ відносно кількості отриманої енергії та не перевищує $3 \%$ від безпосередньо вимірюваних значень: температури теплоносія з різних джерел теплопостачання, отриманої теплової енергії, швидкості течії, температури води в контейнері на виході з бак-акумулятора та електрич- ної потужності циркуляційних насосів і т. ін.

Опис модельованої системи рівнянь здійснювався на основі рівнянь регресії другого ступеня з інтеракціями. Статистичні методи моделювання експериментів дали змогу, у нашому випадку, зменшити кількість експериментів у 20 разів, що у підсумку становило 31 експеримент.

Шукана функція $y_{k}=f\left(x_{1}, x_{2}, x_{3}, \ldots, x n\right)$, що $€$ сумою багаточленів другого ступеня, визначалася наступним рівнянням: $y_{k}=b_{0}+b_{i} x_{i}+b_{i j} x_{i} x_{j}+b_{i i} x_{i}^{2}$, (13)

де: $b_{0}-$ означає вільний член, який описує вихідний параметр, при $x=0$ (нульовий рівень);

$b_{i}-$ коефіцієнти, які описують вплив лінійних залежностей окремих параметрів шуканих $x_{n}$ на вихідний параметр $y_{k}$;

$b_{i j}$ - коефіцієнти, які описують вплив лінійних за- 
TEХНІЧНІ НАУКИ

лежностей, поєднання змінних шуканих факторів $x_{i} x_{j}$ на вихідний параметр $y_{k}$;

$b_{i i}$ - коефіцієнти, які описують вплив квадратичної залежності окремих шуканих факторів $x_{n}$, на вихідний параметр $y_{k}$.

\section{1. Значення досліджуваних параметрів}

\begin{tabular}{|c|c|c|c|c|}
\hline \multirow{2}{*}{$\begin{array}{l}\text { Код } \\
\text { вимірювання }\end{array}$} & \multicolumn{4}{|c|}{ Досліджувані чинники (змінні) } \\
\hline & $\begin{array}{c}\mathrm{x}_{1}\left(\mathrm{t}_{\mathrm{a}}\right) \\
{\left[{ }^{\mathrm{O}} \mathrm{C}\right]}\end{array}$ & $\begin{array}{c}x_{2}\left(t_{b}\right) \\
{\left[{ }^{\mathrm{O}} \mathrm{C}\right]}\end{array}$ & $\begin{array}{c}x_{3}\left(t_{c}\right) \\
{\left[{ }^{\circ} \mathrm{C}\right]}\end{array}$ & $\begin{array}{c}x_{4}\left(V_{c}\right) \\
{\left[\mathrm{M}^{3} / \text { год] }\right.}\end{array}$ \\
\hline-2 & 50 & 45 & 30 & 0,05 \\
\hline-1 & 60 & 55 & 35 & 0,01 \\
\hline 0 & 70 & 65 & 40 & 0,015 \\
\hline+1 & 80 & 75 & 45 & 0,0402 \\
\hline+2 & 90 & 85 & 50 & 0,25 \\
\hline Крок вимірювання & 10 & 5 & 5 & 0,05 \\
\hline
\end{tabular}

\section{2. Отримані значення коефіціснтів шуканого рівняння регресї}

\begin{tabular}{|c|c|c|c|}
\hline \multirow{2}{*}{$№$} & \multirow{2}{*}{$\begin{array}{c}\text { Коефіцієнти рівняння } \\
\text { регресії }\end{array}$} & \multicolumn{2}{|c|}{ Значення рівняння } \\
\cline { 3 - 4 } & $b_{0}$ & 3,5207 & емпіричні \\
\hline 1. & $b_{1}$ & $-0,2128$ & 3,5242 \\
\hline 2. & $b_{2}$ & 0,1317 & $-0,0030$ \\
\hline 3. & $b_{3}$ & 0,1463 & 0,1602 \\
\hline 4. & $b_{4}$ & 0,0232 & 0,1014 \\
\hline 5. & $b_{11}$ & $-0,0055$ & 0,2722 \\
\hline 6. & $b_{12}$ & $-0,0679$ & $-0,0002$ \\
\hline 7. & $b_{13}$ & 0,0017 & $-0,0027$ \\
\hline 8. & $b_{14}$ & $-0,0232$ & 0,0006 \\
\hline 9. & $b_{22}$ & $-0,0311$ & $-0,0061$ \\
\hline 10. & $b_{23}$ & $-0,0182$ & $-0,0012$ \\
\hline 11. & $b_{24}$ & 0,0073 & $-0,0073$ \\
\hline 12. & $b_{33}$ & $-0,0045$ & 0,0019 \\
\hline 13. & $b_{34}$ & 0,0276 & $-0,0184$ \\
\hline 14. & $b_{44}$ & $-0,0117$ & 0,0719 \\
\hline 15. & & & $-0,0207$ \\
\hline
\end{tabular}

3. Ранжсвання факторів $x_{i}$ у відповідності до ӥх лінійного впливу

\begin{tabular}{|c|c|c|c|}
\hline $\begin{array}{c}\text { Порядок } \\
\text { істотності } \\
\text { впливу }\end{array}$ & $\begin{array}{c}\text { Досліджуваний } \\
\text { параметр }\end{array}$ & $\begin{array}{c}\text { Закодовані значення } \\
\text { коефіцієнтів рівняння } \\
\text { регресії }\end{array}$ & $\begin{array}{c}\text { Відсоткове співвідношення впливу } \\
\text { досліджуваних параметрів }\end{array}$ \\
\hline 1. & $x_{1}$ & $-0,2128$ & $41,40 \%$ \\
\hline 2. & $x_{2}$ & 0,1463 & $28,46 \%$ \\
\hline 3. & $x_{3}$ & 0,1317 & $25,64 \%$ \\
\hline 4. & $x_{4}$ & 0,0232 & $4,51 \%$ \\
\hline
\end{tabular}

\section{4. Результат однокритерійної оптимізації}

\begin{tabular}{|c|c|c|c|c|}
\hline № & Змінна $x_{\mathrm{i}}$ & Код вимірювання & Коефіцієнт впливу & Одиниця виміру \\
\hline 1. & $t_{a}$ & -2 & 35 & {$\left[{ }^{\circ} \mathrm{C}\right]$} \\
\hline 2. & $t_{b}$ & 2 & 10 & {$\left[{ }^{\circ} \mathrm{C}\right]$} \\
\hline 3. & $t_{c}$ & 2 & 3,5 & {$\left[{ }^{\circ} \mathrm{C}\right]$} \\
\hline 4. & $V_{c}$ & 2 & 5,0 & {$\left[\mathrm{M}^{3} /\right.$ год $]$} \\
\hline 5. & $e_{\max }$ & - & 4,76 & {$[-]$} \\
\hline
\end{tabular}




\section{ТЕХНІЧНІ НАУКИ}

За шукані значення прийнято: $x_{1}-$ температура теплоносія на вході до бак-акумулятора $t_{a}\left[{ }^{0} \mathrm{C}\right]$; $x_{2}$ - температура теплоносія на виході 3 бакакумулятора $t_{b}\left[{ }^{0} \mathrm{C}\right] ; x_{3}-$ температура води на виході 3 бак-акумулятора $t_{c}\left[{ }^{0} \mathrm{C}\right] ; x_{4}-$ потік води на виході 3 бак-накопичувача $V_{c}\left[\mathrm{~m}^{3} /\right.$ год].

В основу проведених нами досліджень покладено, що кількість незалежних факторів, що мають істотний вплив на показники ефективності геліосистеми, становить 4. Вважалося також, що кожна змінна може набувати до 5 різних значень. Тобто, для повного аналізу процесу розглядалося $5^{4}=625$ варіантів.

У таблиці 1 представлено значення досліджуваних за різних режимів роботи.

Коефіцієнти регресії визначено і представлено у таблиці 2.

Шукане рівняння регресії $y=f\left(x_{1}, x_{2}, x_{3}, x_{4}\right)$ має вигляд:

$y=3,5207-0,2128 x_{1}+0,1317 x_{2}+0,1463 \cdot x_{2}+$ $0,1463 \cdot x_{3}+0,0232 \cdot x_{4}-0,0055 \cdot x_{1}^{2}-0,0679 \cdot x_{1} x_{2}$ $+0,0017 \cdot x_{1} x_{3}-0,0232 \cdot x_{1} x_{4}-0,0311 \cdot x_{2}^{2}-$ $0,0182 \cdot x_{2} x_{3}+0,0073 \cdot x_{2} x_{4}-0,0045 \cdot x_{3}^{2}+$ $0,0276 \cdot x_{3} x_{4}-0,0117 \cdot x_{4}^{2}$

Перевірку адекватності емпіричних співвідношень проводили за допомогою дисперсійного аналізу. За критерієм Фішера перевірено початкову гіпотезу $H_{0}$ адекватності математичної моделі. Значення розрахованого критерію Фішера повинно бути менше критичного значення для заданої імовірності $p$ і кількості ступенів свободи $f$.

Коефіцієнт множинної кореляції $R=0,9662$.

Максимальне відхилення $\quad \Delta Z_{\max }=0,1726$.

Середньоквадратичне відхилення $M=0,0705$.

Стандартне відхилення $\quad \sigma=1,1$.

Дисперсія

$\sigma^{2}=1,20$.

На основі представленої вище залежності можна виставити досліджувані параметри $x_{i}$ у порядку збільшення істотності їх лінійних впливів на параметр, що оптимізується $y$ (ККД) (табл. 3).

Знак «+» біля числових змінних коефіцієнтів $x_{2}, x_{3}, x_{4}$ означає додатнє направлення впливу досліджуваного чинника $x_{1}$ на оптимізований параметр $y\left(x_{2}=0,1317, x_{3}=0,1463, x_{4}=0,0232\right)$, натомість знак «-» позначає від'ємне направлення впливу досліджуваного чинника $\left(x_{1}=-0,2128\right)$.

\section{БІБЛІОГРАФІЯ}

1. Bilicki Z. Metody komputerowe w technice cieplnej / [Z. Bilicki, J. Cieśliński, S. Doerffer, R. Kwidzyński i inne]. - Gdańsk : Wydawnictwo Instytutu
Чим більше числове значення коефіцієнта рівняння регресії, тим більшим є вплив (додатний або від'ємний) цього параметра на результат процесу.

3 аналізу слідує, що найбільший вплив $(41,4 \%)$ на значення ефективності геліосистеми (ККД) має параметр $x_{1}$ (температура теплоносія на вході до бак-акумулятора $t_{a}$ ).

Математичний опис досліджуваного процесу за допомогою лінійної залежності можна представити, відкинувши члени вищого порядку. 3 цього слідує рівняння:

$$
y=3,5271-0,2128 x_{1}+0,1317 x_{2}+0,1463 x_{3}
$$

$+0,232 x_{4}$.

Оптимізачія параметрів роботи з огляду на коефіиієнт ефективності геліоустановки. На основі отриманих результатів досліджень проведено оптимізацію (методом системного аналізу та варіаційними методами) - з метою визначення оптимальних параметрів процесу 3 огляду на критерії прийнятої цільової функції: $y=f\left(x_{1}, x_{2}, x_{3}, x_{4}\right)$.

\section{Однокритеріальна оптимізачія:} $y=f\left(x_{1}, x_{2}, x_{3}, x_{4}\right) \rightarrow \max$.

Для сформульованої оптимізаційної задачі представлено розв'язання проблеми методами Хука-Дживса та Гауса-Зейделя, результати якого наведено у таблиці 4.

Отже, максимальну кількість енертії можна

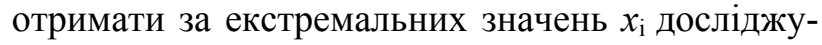
ваної області $\left(x_{1}=-2, x_{2} \div x_{4}=+2\right)$.

Висновок. У результаті проведених досліджень із використанням математичного моделювання виявлено особливості впливу обраних параметрів роботи геліоустановки на теплову продуктивність теплообмінника.

Дослідження ефективності сонячного вакуумного колектора та результати моделювання доводять доцільність використання цього виду обладнання в умовах Малопольського регіону.

Вони практично повністю перекривають потреби в енергії для підігріву гарячої води в період із травня по вересень, а загальнорічний ККД становить $\approx 37,7 \%$.

Аналіз проведено за умов, що середньорічна інтенсивність сонячного випромінення для умов Кракова складає $350 \mathrm{BT} / \mathrm{m}^{2}$.

Maszyn Przepływowych PAN, 1996. - S. 14-16.

2. Dyrektywa Parlamentu Europejskiego i Rady 2009/28/WE z dnia 23.04.2009 r. - Офіц. вид. - 
S. 4-42. - (Нормативний документ СС).

3. EurObserv'er Parsi. France partner Instytutu Energetyki w Warszawie / EurObserv'er Parsi // Zbiurka prac Instytutu Energetyki w Warszawie. Wrzesień, 2007. - S. 17-48

4. Gogót $W$. Konwersja termiczna energii promieniowania słonecznego $\mathrm{W}$ warunkach krajowych. Ekspertyza Komitetu Termodynamiki i Spalania PAN / W. Gogół. - Warszawa : Oficyna wydawnicza Politechniki Warszawskiej, 1993. S. 42-45.

5. Górecka R. Teoria i technika eksperymentu / R. Górecka // Skrypt Politechniki Krakowskiej. Kraków, 1995. - S. 25-26.

6. Greń J. Statystyka matematyczna. Modele i zadania / J. Greń. - Warszawa : PWN, 1982. - S. 8-10.

7. Jędrysek M.-O. Wybrane zagadnienia z zakresu OŻE / M.-O. Jędrysek // Ministerstwo Środowiska. 2007. - S. 28-35.

8. Kopecki M. Wybór optymalnego rozwiązania a zagadnienie tzw. wielokryterialności na przykładzie Kompleksowej gospodarki paliwowo-energetycznej / M. Kopecki // Archiwum Energetyki. - 1976. № 4. - S. 15-18.

9. Konferencja dotycząca OŹE : Praca zbiorowa
(Karniowice 12.03.2008) / Małopolski Ośrodek Doradztwa Rolniczego. - Karniowice : Wyd. MODR, 2008. - S. 36-38.

10. Kotowski W. Gigawat Energia / W. Kotowski, E. Konopka // Zbiurka Prac Energetycznych. 2008. - S. 23-28.

11. Pietraszko S. M. Ogniwa i systemy fotowoltaiczne / S. M. Pietraszko // Fotowoltaika Polska PVPL. 2000. - S. 68-78.

12. Placha $D$. Wyniki badań układów solarnych w laboratorium OŹE w ZSE nr $1 \mathrm{w}$ roku 2008 /

D. Placha. - Kraków : OŻE. - №1, 2008. - S. 5-19.

13. Raport Ministerstwa Gospodarki z dn. 02.04.2008 r. - Офіц. вид. - S. 33-42.

14. Tytko $R$. Odnawialne żródła energii / R. Tytko. - Warszawa : OWG, 2011. $-576 \mathrm{~s}$.

15. Блюм Я. Б. Новітні технології біоконверсії / [Я. Б. Блюм, Г. Г. Гелетуха, І. П. Григорюк, В. О. Дубровін та ін.]. - К. : «Аграр Медіа Груп», 2010. - $326 \mathrm{c}$.

16. Петренко I. П. Україна та Польща: на шляху до розширення інвестицій у енергозбереження / Петренко І. П. // Збірник наукових праць національного університету державної податкової служби України, 2010. - № 1. - С. 316-323. 